\title{
Mixed Connective Tissue Disease Highlighting Diagnostic Exigency and Treatment Woes
}

\author{
Sabahat Zamani Nagma, Nabila Afsar*, Idrees Akhtar Afroze and Atiya Begum \\ Department of Pathology, Deccan College of Medical Sciences, India
}

\section{ABSTRACT}

Mixed connective tissue disease (MCTD) is a rare connective tissue disease characterized by manifestations that overlap symptoms typical of several other inflammatory diseases of connective tissue. A presence of anti-ribonucleoprotein antibodies (antiU1RNP) in high titer is a typical immunological finding.

A 20 year old female complained of chilling and cyanosis of fingers on cold exposure since 5 years, with pain and numbness, hardening of skin of both hands, episodes of Raynaud's phenomenon, gangrenous changes, self amputation of distal digit of middle finger. Systemic manifestations were also associated. A 15 year old female complained of thickening and tightening of skin of face and hands since 5 months, associated with joint pains, shortness of breath, dysphagia and photosensitivity of skin. Both cases were positive for Anti U1-RNP and AntiSSA/Ro52 antibodies. Serology, radiology and histopathology were performed.

MCTD may be difficult to define as definite classification criteria are not fulfilled. Young and pediatric patients with skin manifestations must be investigated to initiate early treatment and monitor renal parameters. Patient compliance and trust in treating physician is a key to early diagnosis and treatment. Treating physician must recognize symptoms and refer patients to higher centres.

Keywords: MCTD, Diagnosis, Raynaud's, Anti-U1RNP

\section{Introduction}

Mixed connective tissue disease (MCTD) is a rare connective tissue disease with autoimmune background. Clinically, it is characterized by manifestations that overlap symptoms typical of several other inflammatory diseases of connective tissue - systemic lupus erythematosus, systemic scleroderma, polymyositis or dermatomyositis, and sometimes rheumatoid arthritis (which is equivalent to juvenile idiopathic arthritis during childhood). A presence of anti-ribonucleoprotein antibodies (antiU1RNP) in high titer is a typical immunological finding. Mixed connective tissue disease should be distinguished from the overlapping syndromes. ${ }^{1-5}$ The criteria of Kasukawa are the most widely used as they are considered to be the most precise ${ }^{1,2}$. They include: symptoms common to all the diseases involved (Raynaud's phenomenon, swollen fingers), presence of specific antiRNP antibodies and selected symptoms typical of each of the particular component disease separately (systemic lupus erythematosus, systemic sclerosis, polymyositis).

The incidence of this condition is about 2.7 per $100,000 .{ }^{1}$ During childhood it usually starts between 2 and 16 years of age (mean - 11 years) and it afflicts girls more frequently2. Symptoms of MCTD usually develop gradually over a few years.

\section{Case Report}

Case 1: A 20 year old unmarried female patient reported to Dermatology Department of Deccan College of Medical Sciences/Owaisi Hospital and Research Centre with history of repeated episodes of chilling and cyanosis of fingers, especially after exposure to cold since 5 years. She complained of pain and numbness of finger tips, along with hardening of skin of both hands and arms. There were episodes of Raynaud's phenomenon followed by gangrenous change and self amputation of the distal digit of middle finger along with skin cracks of these regions. She also complained of dysphagia, dyspnea, joint pain and gastroesophageal reflux. She gave history of cough with expectoration which was blood stained(hemoptysis) associated with intermittent fever, loss of appetite and weight.

On examination, finger tip scarring with amputated distal digit of middle finger of right hand (Fig 1) and sclerodactyly was noted. There were few hypopigmented patches seen on the left side of the face and bilateral upper and lower limbs. There was salt pepper appearance of body with discrete distribution. The nose had a pinched appearance. Facial skin was normal with positive skin pinching and no skin tightening. 
Laboratory investigations were performed, which showed low $\mathrm{Hb}$ of $9.8 \mathrm{~g} / \mathrm{dl}$, normal total and differential white blood cell count and adequate platelets. Reticulocyte count was within normal limit $(0.5 \%)$. Erythrocyte sedimentation rate was raised $(35 \mathrm{~mm} / 1 \mathrm{st}$ hour). Serum creatinine $(0.9$ $\mathrm{mg} / \mathrm{dl})$, Blood Urea $(11 \mathrm{mg} / \mathrm{dl})$, random blood sugar $(117 \mathrm{mg} / \mathrm{dl})$ and Serum electrolytes were all within normal biological ranges. Urine and Stool examination showed no abnormalities. Bleeding time and clotting time were normal. Sputum for AFB was negative. On Serological testing for Salmonella typhi $\mathrm{O}$ and $\mathrm{H}$ titres were less than $<1: 20$, however Salmonella paratyphi AH showed a high titre of more than 1:320.

ANA profiling by blot method showed Positive anti SS-A/ Ro-52 and anti U1-RNP, negative anti CENP-B and anti Scl-70. Bone marrow aspiration revealed megaloblastoid marrow reaction. Upper GI endoscopy revealed antral gastritis and lax lower oesophageal sphincter.

CECT findings revealed irregular mural thickening of greater curvature of stomach with homogenous contrast enhancement in the cardia, fundus and proximal body region (max thicknesss 12mm). Mild circumferential irregular mural thickening of oesophagogastric junction with irregular luminal narrowing was also noted. Mild dilated contrast filled esophagus was noted. Parenchyma of both lungs showed multiple tiny centrilobular nodular opacities noted-infective etiology. No significant abnormality seen in other organs.

Skin biopsy on histopathological examination revealed epidermis showing mild hyperkeratosis, thinned out

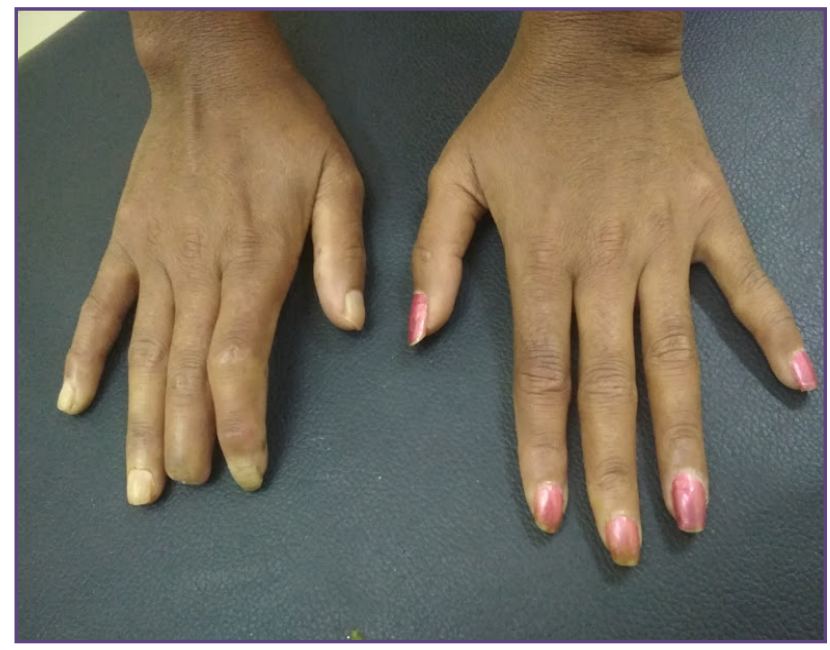

Fig.1: image of both hands of patient, right hand showing fingertip scarring and self amputation of distal digit of middle finger. epidermis with focal loss of rete ridges. There was eosinophilic fibrocollagenous and hyalinised fibrous tissue in dermis along with edema and perivascular infiltrate of lymphocytes and thickened arteriole. The histopathological features were consistent with systemic sclerosis.(Fig.2)

Case 2: A 15 year old female presented to Dermatology Department of Deccan College Medical Sciences / Owaisi Hospital and Research Centre with complaints of thickening and tightening of skin of face and hands since 5 months. She also complained of joint pains, shortness of breath, dysphagia and photosensitivity of skin.

On examination, tightening of skin was noted along with salt and pepper pigmentation of both upper and lower limbs. Fingertip scarring was noted. Tongue was noted to be bald.

Investigations revealed positive anti U1-RNP, ANA and anti SSA antibodies. Other investigations CBP-which showed low Hemoglobin of $8.9 \mathrm{~g} / \mathrm{dl}$, normal total and differential white blood cell count and adequate platelets. Erythrocyte sedimentation rate was raised $(48 \mathrm{~mm} / \mathrm{lst}$ hour). Biochemical parameters including serum creatinine, Blood Urea, random blood sugar and Serum electrolytes were all within normal biological ranges.

Skin biopsy on histopathological examination revealed the epidermis showed basal cell vacuolar degeneration and pigment incontinence. The dermis showed fibrosis. There is inflammatory infiltrate of lymphocytes and eosinophils in the upper and reticular dermis and around blood vessesls and adnexa(Fig.3). The histopathological features were consistent with mixed connective tissue disorder.

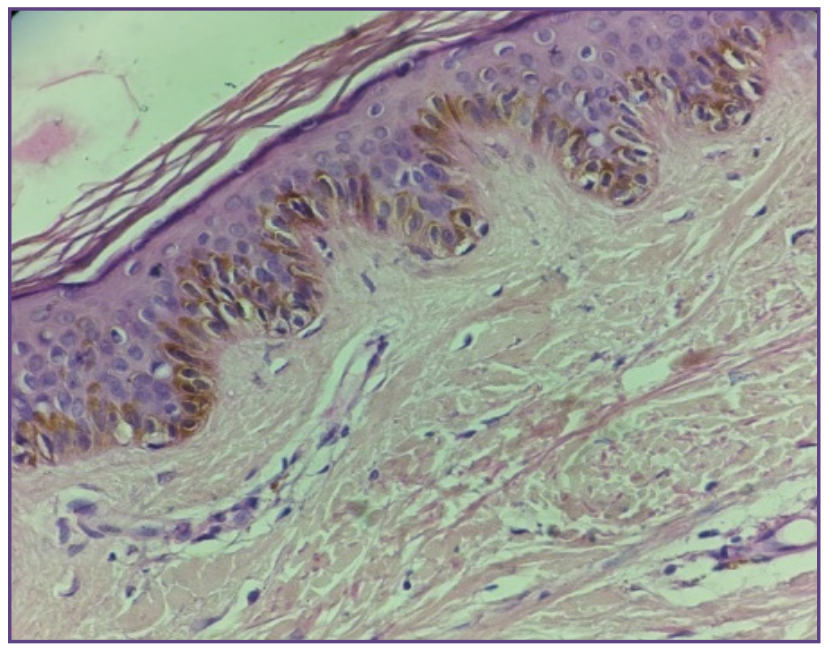

Fig. 2: 40X H\&E microscopic image of skin biopsy showing mild hyperkeratosis, thinned out epidermis with focal loss of rete ridges and eosinophilic fibrocollagenous and hyalinised fibrous tissue in dermis. 


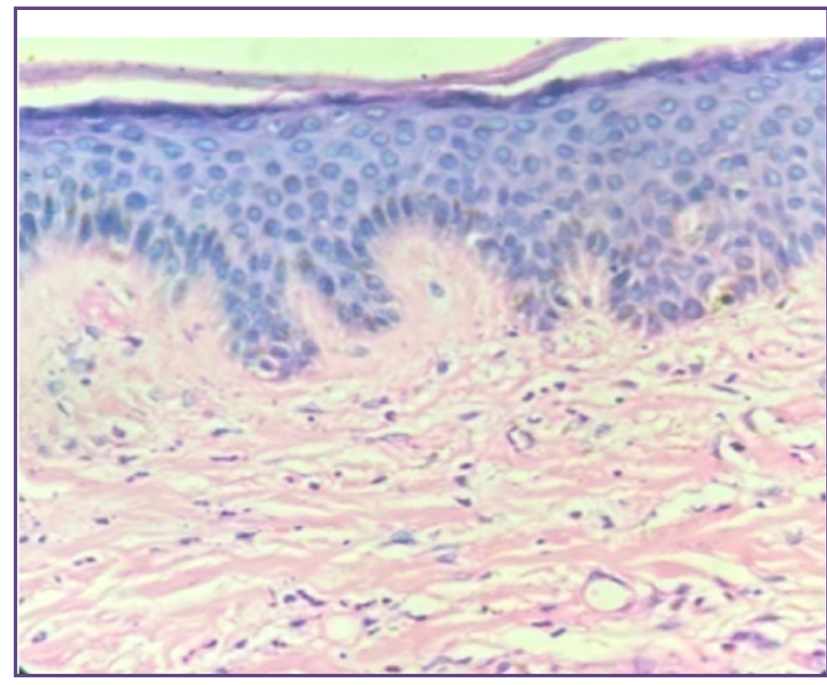

Fig. 3: 40X H\&E image of skin biopsy showing basal cell vacuolar degeneration and pigment incontinence and dermal fibrosis.

\section{Discussion}

Hardening and tightening of skin of fingers, especially fingertips, with a tendency to skin cracking of those regions independently of trauma or other external factors, were the first symptoms that prompt the patients to seek medical advice. Diseases with "hard skin" include systemic scleroderma (SS) and a series of sclerodermalike disorders 6, 7,8. They differ in etiology, pathogenesis, clinical course and prognosis. Systemic sclerosis is a heterogeneous autoimmune disorder characterized by microvascular injury, fibrosis of the skin and other organs, and presence of antinuclear autoantibodies (ANA) with a prevalence varying from 80 to $98 \%$. The ANA classically detected in SS include anti-centromere (ACA) and antitopoisomerase I (ATA), which are positive in $50-60 \%$ of the patients ${ }^{9}$. ANA profiling in the present cases showed Positive U1-RNP and anti-SSA/Ro-52and were negative for CENP-B(ACA) and Scl-70(ATA).

Esophageal involvement is frequent in $\mathrm{SSc}$, occurring in as many as $50 \%$ to $90 \%$ of patients. ${ }^{10}$ In case 1 , antral gastritis and lax lower oesophageal sphincter was noted. Complaints of dysphagia were noted in case 2 , however the endoscopic findings could not be retrieved from patient records.

Golding maintains that skin is involved in all cases of MCTD which are initially diagnosed as systemic lupus erythematosus, systemic sclerosis or dermatomyositis and that the first symptoms include Raynaud's phenomenon and swelling of the hands ${ }^{11}$. These symptoms was presenting both the patients from the very beginning of the disease.
Moreover, Golding describes a unique case of MCTD in an 18-year-old girl, in whom skin involvement presented as morphea without any other dermatological or systemic symptoms of $\mathrm{SS}^{11}$.

Swart and Wulffraat noticed that on average it took 1.7 years from the first symptoms to finally establish the diagnosis of MCTD. They also found that at the early stage of the disease, SS is diagnosed only in $0-3 \%$ of pediatric patients because at that time symptoms of myositis or SLE predominate in children. It is thought that in the developmental period MCTD has a milder course than in adult patients, and that the disease activity gradually decreases and after a few years it becomes low ${ }^{2}$. In case 1 , the final diagnosis was established after 5 years of appearance of first symptoms. The delay in diagnosis was probably due to non compliance by the patients and their inability to avoid doctor shopping, in the pursuit of rapid recovery. In case 2, the diagnosis was established at 5 months from initial appearance of symptoms. This could be due to early referral to a tertiary care centre where patient could be thoroughly worked up.

It is generally thought that muscle involvement in MCTD is subclinical and usually presents as elevated levels of muscle enzymes. Both the present patients had no clinical symptoms of muscle damage however they complained of joint pains.

Essalah et al. described an 18-year-old girl with a 13year history of MCTD with a morbid course, who developed glomerulonephritis similar to lupus nephritis with subsequent renal insufficiency and scleroderma-like gastrointestinal disease ${ }^{12}$. Both the patients described in this present study had no evidence of internal organ involvement so far.

\section{Conclusion}

Different forms of connective tissue diseases, especially at early phases, may be very difficult to define, due to which it may take several months or years to establish the final diagnosis. Diagnosis must be made based on clinical, serological and histopathological manifestation, as definite classification criteria for a specific disease are not fulfilled. All young and pediatric patients with skin manifestations must be investigated serologically and histopathologically for early diagnosis of MCTD so that treatment can be initiated at the earliest and renal monitoring may be done regularly.

Considering both the cases presenting to our institute, it was also noted that communication between doctor and patient ideally necessitates a certain degree of reciprocity. 
Patient compliance and trust in treating physician is a key to early diagnosis and treatment. In return, the treating family physician must recognize the symptoms and refer such patients immediately to appropriate higher centers to enable proper and prompt diagnosis and management.

\section{Abbreviations}

MCTD:Mixed connective tissue disease

SLE: Systemic lupus erythromatosis.

ANA: Antinuclear antigen

SS: Systemic sclerosis

\section{Acknowledgements}

We would like to acknowledge the supporting staff, the dermatology department and the administration for the support provided.

\section{Reference}

1. Puszczewicz M. Mieszana choroba tkanki łącznej. In: WielkaInterna. Reumatologia [Polish]. Puszczewicz M (ed.). MedicalTribune Polska, Warsaw 2010; 157-62.

2. Swart JF, Wulffraat NM. Diagnostic workup for mixed connectivetissue disease in childhood. Isr Med Assoc J 2008;10: 650-2.

3. Hoffman RW, Maldonado ME. Immune pathogenesis of mixed connective tissue disease: a short analytical review. Clin Immunol 2008; 128: 8-17.

4. Ortega-Hernandez OD, Shoenfeld Y. Mixed connective tissue disease: an overview of clinical manifestations, diagnosis and treatment. Best Prac Res Clin Rheumatol 2012; 26: 61-72.
5. Zimmermann-Górska I. Mieszana choroba układowa tkanki łącznej i zespoły nakładania. In: Złota Seria Interny Polskiej. Reumatologia kliniczna [Polish]. Zimmermann-Górska I (ed.).Wydawnictwo Lekarskie PZWL, Warsaw 2009; 695700 .

6. Sierakowski S, Sierakowska M. Choroby twardzinopodobne. In: Złota Seria Interny Polskiej. Reumatologia kliniczna [Polish]. Zimmermann-Górska I. Wydawnictwo LekarskiePZWL, Warsaw 2009: 624-38.

7. Zulian F, Vallongo C, Woo P, et al. Localized scleroderma in childhood is not just a skin disease. Arthritis Rheum 2005;52: 2873-81

8. Joanna Latuśkiewicz-Potemska, Agnieszka Zygmunt, Małgorzata Biernacka-Zielińska, Jerzy Stańczyk, Elżbieta Smolewska; Mixed connective tissue disease presenting with progressive scleroderma symptoms in a 10-year-old girl Postępy Dermatologii i Alergologii 334 5, October / 2013

9. Villalta D, Imbastaro T, Di Giovanni S, Lauriti C, Gabini M, Turi MC, Bizzaro N. Diagnostic accuracy and predictive value of extended autoantibody profile in systemic sclerosis.

10. Isabelle marie, stephane dominique, herve' levesque,philippe ducrotte',philippe denis, marie-france hellot, and hubert courtois Esophageal Involvement and Pulmonary Manifestations in Systemic Sclerosis;American College of Rheumatology Published by Wiley-Liss, Inc. August 2001 Vol. 45 , No. 4

11. Golding DN. Morphoea (localised scleroderma) in a patient with mixed connective tissue disease. Ann Rheum Dis 1986;45: 523-5.

12. Essalah AA, Eddy AA. A morbid course in a girl with mixed connective disease. Pediat Nephrol 1999; 13: 54-6.

*Corresponding author:

Dr. Nabila Afsar, 5-5-203/3,Patel Nagar, Nampally Hyderabad-500001 Telengana India

Phone: +91 9848020386

Email: nabila_dr@yahoo.com

Financial or other Competing Interests: None. 